УДК: 53.043

\title{
ЭНТРОПИЙНАЯ АГРЕГАЦИЯ УНТ В ВЫСЫХАЮЩЕЙ КАПЛЕ НА ГИДРОФИЛЬНОЙ И ГИДРОФОБНОЙ ПОДЛОЖКЕ
}

\author{
ㄷ2018 И. И. Долгих, Л. А. Битюцкая \\ Воронежский государственный университет, Университетская пл. 1, 394018 Воронеж, Россия \\ e-mail:dolgih_igor@yahoo.com
}

Поступила в редакцию 05.09.2018

\begin{abstract}
Аннотация. При изучении агрегации углеродных нанотрубок в условиях гидродинамической неустойчивости высыхающей капли на гидрофобных и гидрофильных подложках выявлена определяющая роль гидродинамических течений. Установлено, что протекание энтропийной агрегации нанотрубок в капле под действием аэросила зависит от типа подложки.
\end{abstract}

Ключевые слова: углеродные нанотрубки, аэросил, агрегация, энтропийная самоорганизация, силы исключенного объема.

DOI: https://doi.org/10.17308/kcmf.2018.20/635

\section{ВВЕДЕНИЕ}

В концентрированном коллоидном растворе движение частиц ограничено взаимным расположением, что приводит к ряду эффектов. В некоторых системах, например биологических, реакции проходят не так как в обычном растворе [1]. При этом отношение эффективной концентрации компонента в растворе к реальной зависит от его геометрии, что приводит к смещению равновесия и изменению скорости реакции [2].

Силы исключенного объема не только ускоряют реакции, но и вызывают эффективное притяжение частиц. При очень высоких концентрациях они способны без участия других сил приводить к объединению частиц, которым не свойственно взаимодействие. Это используется для сборки мембран и коллоидных кристаллов из стержневых молекул [3].

Биологические системы представляют собой коллоидный раствор, в котором свободный объем, доступный для движения частиц, сравним с их размерами, поэтому энтропийные силы в них велики и определяют многие процессы [4]. Искусственно такой сильно населенный раствор получают, используя молекулы вытеснители - молекулы, которые занимают много объема и ни с чем не взаимо- действуют. Также получить такой населенный раствор можно при высыхании капли, при этом, контролируя процесс высыхания, можно управлять энтропийной самоорганизацией [5]. При проведении реакции в капле большую роль играет динамика испарения, поскольку данный процесс неравновесный [6]. При высыхании капли возникают сильные течения, сносящие растворенные вещества к краю капли, образуя кольцо [7]. Течения в коллоидном растворе вызывают упорядочивание и являются одним из способов получения коллоидных кристаллов $[8,9]$.

Согласно модели Асакуры [10] эффективная сила притяжения, определяемая исключенным объемом, пропорциональна осмотическому давлению, которое меньшие по размеру частицы оказывают на поверхность больших, а, следовательно, их температуре и концентрации [11]. Стержневые частицы самоорганизуются особенно хорошо, поскольку для них исключенный объем велик, однако для слишком длинных сказывается снижение подвижности [12]. Этой силой можно управлять с помощью локальных неоднородностей раствора, создаваемых потоком [13] и градиентом температур [14]. Неравновесные силы исключенного объема могут быть больше во много раз и используются для получения колло- 
идных кристаллов. Для создания неоднородности в данной точке, например, используют импульсы тонко сфокусированного лазера [15].

Влияние типа подложки на энтропийную самоорганизаию в капле недостаточно изучено. Целью данной работы является изучение влияния типа смачивания подложки на протекание агрегации нанотрубок в высыхающей капле.

\section{МАТЕРИАЛЫ И МЕТОДЫ}

Для исследования агрегации использовали углеродные нанотрубоки диаметром 20-40 нм и длинной 1 мкм. Взвесь нанотрубок в дистиллированной воде в концентрации 0.1 мг/мл диспергировали ультразвуком в течение 5 минут на диспергаторе УЗГ-13. В качестве агента, вызывающего энтропийную агрегацию, использовали аэросил в концентрации 0.1 мг/мл, который также диспергировался в течение 5 минут. В качестве хорошо смачиваемой подложки использовали предметное стекло, а в качестве гидрофобной - медицинский парафин.

Капля массой 1 мг наносилась на подложку, после чего за её испарением наблюдали через оптический микроскоп, снабженный камерой, кроме того, масса капли отслеживалась с помощью аналитических весов. По очереди наблюдалось высыхание капель, содержащих: 1) раствор чистого аэросила; 2) раствор чистых нанотрубок; 3) смесь растворов аэросила и нанотрубок в соотношении 1:1. Длинные нанотрубки были выбраны, поскольку они, в отличие от коротких, не вступают в реакцию с аэросилом, что позволяет применить модель Асакуры и считать, что взаимодействие определяется только исключенным объемом.

\section{РЕЗУЛЬТАТЫ}

На смачиваемой поверхности стекла площадь капли не может измениться, что приводит к линейной скорости испарения (рис. 1). Сильные течения выносят чистый аэросил на край капли. Образуется ярко выраженное кольцо согласно «кофейной» модели. Однако скопления чистых нанотрубок слишком велики и не сносятся течениями, оставаясь распределенными по объему вплоть до высыхания. При добавлении во взвесь нанотрубок аэросила меняется тип агрегации от неупорядоченных структур к упорядоченным - жгуты со средним диаметром 1 мкм (рис. 2). Это изменение можно трактовать с позиций исключенного объема. На гидрофобном парафине капля непрерывно меняет свою площадь и, следовательно, скорость испарения, даже несмотря на присутствие нанокомпонентов, которые должны были бы сформировать кольцо и препятствовать сжатию капли. Скопления нанотрубок сжимаются вместе с каплей, образуя после высыхания клубок в центре капли (рис. 3). Аэросил на гидрофобной поверхности также не образует кольца. Хаотичные движения взвешенных агрегатов нанотрубок свидетельствуют об отсутствии заметных гидродинамических течений.

\section{ВЫВОДЫ}

Установлено, что протекание энтропийной агрегации нанотрубок в капле под действием аэросила зависит от типа подложки. На гидрофильной подложке образуются разветвленные структуры, а кроме того жгуты, обладающие видимой жесткостью и устойчивостью. На гидрофобной поверхности происходит равномерное сжатие капли с измене-

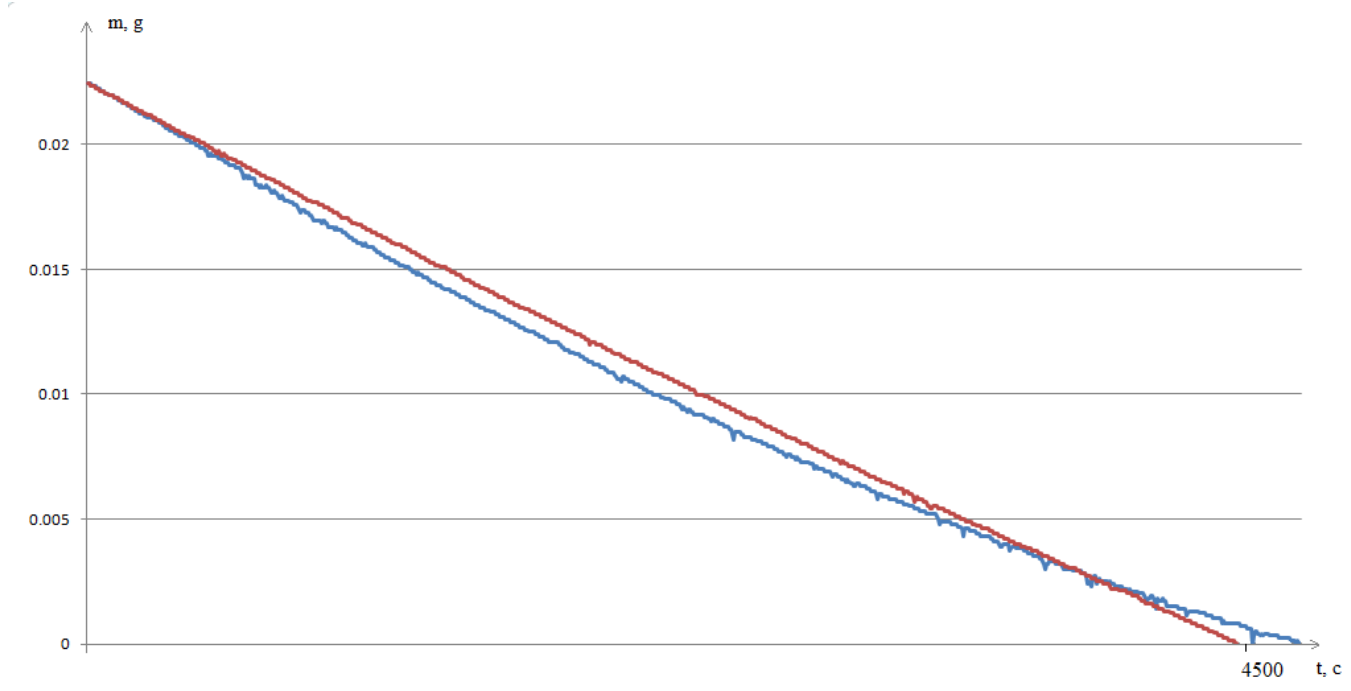

Рис. 1. Изменение скорости испарения на гидрофильной и гидрофобной поверхности [Fig. 1. Change in the rate of evaporation on a hydrophilic and hydrophobic surface] 

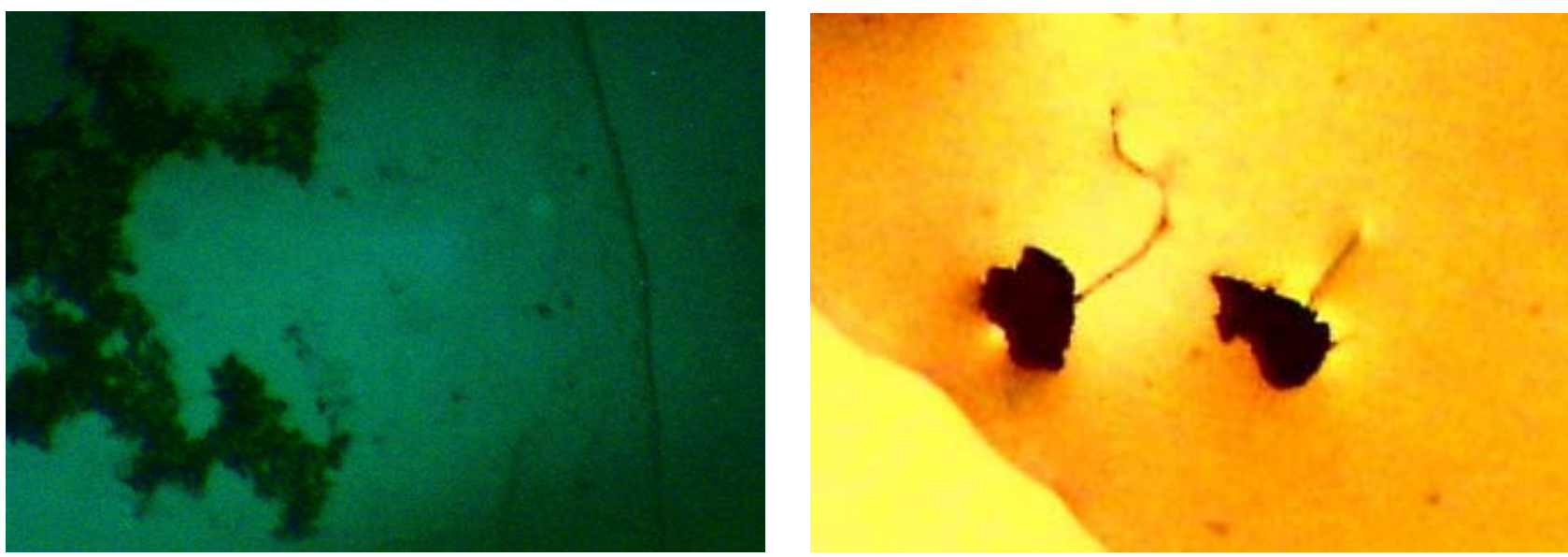

Рис. 2. Распределенная агрегация на гидрофильной подложке: $a$ - чистые нанотрубки; $b-$ с добавлением аэросила [Fig. 2. Distributed aggregation on a hydrophilic substrate: $a$-clean nanotubes; $b$ - with the addition of aerosol]

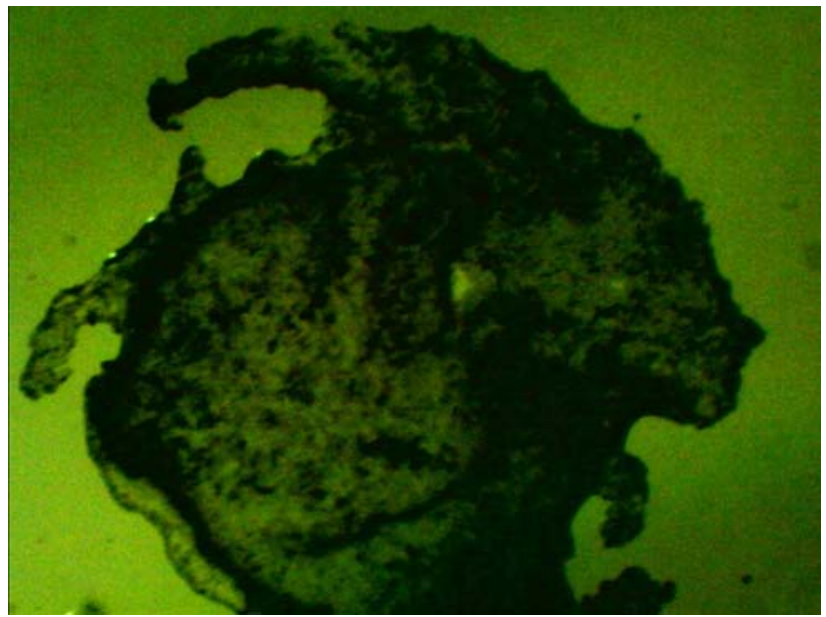

Рис. 3. Кумулятивная агрегация на гидрофобной подложке

[Fig. 3. Cumulative aggregation on a hydrophobic substrate]

нием диаметра от 5 до 0.5 мм. Скопления нанотрубок не проявляют признаков упорядочивания, a c уменьшением размеров капли стягиваются в клубок. Образование упорядоченных жгутов трубок на гидрофильной поверхности свидетельствует о взаимосвязи капиллярных потоков и сил исключенного объема (энтропийных сил) в условиях высыхающей капли. Сближение нанотрубок приводит к усилению взаимодействия, увеличению жесткости, и, как результат, самовыпрямлению трубок.

Работа выполнена при финансовой поддержке РФФИ (проект № 16-43-360281 p_a).

\section{СПИСОК ЛИТЕРАТУРЫ}

1. Minton A. P. // J. of Cell Science, 2015, vol. 119, № 14, pp. 2863-2869. DOI: https://doi.org/10.1242/ jes. 03063
2. Minton A. P. // J. of Biological Chemistry, vol. 276, № 14, pp. 10577-10580. DOI: https://doi.org/10.1074/jbc. r100005200

3. Barry E., Dogic Z. // PNAS, 2010, vol. 107, № 23, pp. 10348-10353. DOI: https://doi.org/10.1073/ pnas. 1000406107

4. Чеботарева Н. А., Курганов Б. И., Ливанова Н. Б. // Биохимия, 2004, т. 69, № 11, с. 1522-1536.

5. Florian Huber, Dan Strehle, Joerg Schnauss, Josef Kas // New J. Physics, 2015, vol. 17, p. 043029. DOI: https://doi.org/10.1088/1367-2630/17/4/043029

6. Rabani E., Reichman D. R., Geissler P. L., Brus L. E. // Nature, 2003, vol. 426, pp. 271-274. DOI: https://doi. org/10.1038/nature02087

7. Deegan R. D., Bakajin O., Dupont T. F., et al. // $\mathrm{Na}-$ ture, 1997, vol. 389, pp. 827-829. DOI: https://doi. org $/ 10.1038 / 39827$

8. Grzelczak M., Vermant J., Furst E. M., et al. // ACS Nano, 2010, vol. 4, № 7, pp. 3591-3605. DOI: https://doi. org $/ 10.1021 / \mathrm{nn} 100869 \mathrm{j}$

9. Gunes D. G., Scirocco R., Mewis J., Vermant J. // J. Non-Newtonian Fluid Mech., 2008, vol. 155, pp. 39-50. DOI: https://doi.org/10.1016/j.jnnfm.2008.05.003

10. Sho Asakura, Fumio Oosawa // J. Polymer Science Part A: General Papers, 1958, vol. 33, № 126, pp. 183-192. DOI: https://doi.org/10.1002/pol.1958.1203312618

11. Bishop K. J., Wilmer C. E., Soh S., Grzybowski B. A. // Small, 2009, vol. 5, № 14, pp. 1600-1630. DOI: https://doi.org/10.1002/smll.200900358

12. Hai-Dong Deng, Guang-Can Li, Hai-Ying Liu // Optics Express, 2012, vol. 20, № 9, p. 9616. DOI: https://doi. org/10.1364/oe.20.009616

13. Jessy L. B., Asaph Widmer-Cooper, Michael F. T., et al. // Nano Letters, 2010, vol. 10, pp. 195-201. DOI: https://doi.org/10.1021/n1903187v

14. Wulfert R., Seiferta U., Speck T. // Soft Matter, 2017, vol. 13, № 48, pp. 9093-9102. DOI: https://doi.org/10.1039/ c7sm01737e 
15. Hong-Ren Jiang, Hirofumi Wada, Natsuhiko Yoshinaga, Masaki Sano // Physical Review Letters, 2009, vol. 102, p. 208301. DOI: https://doi.org/10.1103/physrev-

lett.102.208301

\title{
ENTROPY DRIVEN AGGREGATION OF CNT IN A DRYING DROP ON HYDROPHILIC AND HYDROPHOBIC SUBSTRATE
}

\author{
(C)2018 I. I. Dolgih, L. A. Bitutskaya \\ Voronezh State University, 1, Universitetskaya pl., 394018 Voronezh, Russia \\ e-mail:dolgih_igor@yahoo.com
}

Received 05.09.2018

\begin{abstract}
Functional materials with desired properties can be assembled from colloidal particles of the necessary materials. However nanoparticles usually exist in a randomly aggregated state, which makes them difficult to separate and organize. The most important and difficult task, at the same time less developed, is not the production of nanoparticles but the assembly of a macroscopic material from them. This study is dedicated to the aggregation of carbon nanotubes by depletion forces and the effect of the hydrophobic and hydrophilic substrate. The process has been realized in a drying droplet of distilled water with colloidal particles and observed with an optical microscope. Colloid $\mathrm{SiO}_{2}$ particles were used as a macromolecule solution causing the depletion forces. Long carbon nanotubes were chosen because they unlike the short ones show no reaction with $\mathrm{SiO}_{2}$. Nanotubes were ultrasonicated in distilled water for $5 \mathrm{~min}$ to obtain a colloidal mixture. The rate of evaporation of the droplet was controlled using analytic scales. It has been shown that the process of aggregation strongly depends on the substrate material. On a hydrophilic substrate the droplet cannot change its area and evaporates at constant speed. The strong capillary flows cause high orientation of nanotubes and organize them into transparent wires. By the contrast on a hydrophobic substrate the droplet shrinks steadily and the rate of evaporation decreases with constant rate. In this case no signs of self organization were detected. As a concentration increases the aggregates of nanotubes that are distributed in a droplet grow but they cannot escape the droplet and deposit on the substrate. As a droplet shrinks steadily all the components move with it and gather at the center creating a clot.

The results may be used in production of functional and combined materials and as a method of segregation of colloids.
\end{abstract}

Keywords: carbon nanotubes, aerosil, aggregation, entropic self-organization, depletion forces.

DOI: https://doi.org/10.17308/kcmf.2018.20/635

\section{ACKNOWLEDGMENTS}

The reported study was supported by the Russian Foundation for Basic Research (project No. 16-43$360281 r_{-} a$ ).

\section{REFERENCE}

1. Minton A. P. J. of Cell Science, 2015, vol. 119, no. 14, pp. 2863-2869. DOI: https://doi.org/10.1242/jcs.03063

2. Minton A. P. J. of Biological Chemistry, vol. 276, no. 14, pp. 10577-10580. DOI: https://doi.org/10.1074/jbc. r100005200

3. Barry E., Dogic Z. PNAS, 2010, vol. 107, no. 23, pp. 10348-10353. DOI: https://doi.org/10.1073/ pnas. 1000406107

4. Chebotareva N. A., Kurganov B. I., Livanova N. B. Biochem., 2004, vol. 69, № 11, p. 1239.
5. Florian Huber, Dan Strehle, Joerg Schnauss, Josef Kas. New J. Physics, 2015, vol. 17, p. 043029. DOI: https:// doi.org/10.1088/1367-2630/17/4/043029

6. Rabani E., Reichman D. R., Geissler P. L., Brus L. E. Nature, 2003, vol. 426, pp. 271-274. DOI: https://doi. org/10.1038/nature02087

7. Deegan R. D., Bakajin O., Dupont T. F., et al. Nature, 1997, vol. 389, pp. 827-829. DOI: https://doi. org/10.1038/39827

8. Grzelczak M., Vermant J., Furst E. M., et al. ACS Nano, 2010, vol. 4, no. 7, pp. 3591-3605. DOI: https://doi. org/10.1021/nn100869j

9. Gunes D. G., Scirocco R., Mewis J., Vermant J. J. Non-Newtonian Fluid Mech., 2008, vol. 155, pp. 39-50. DOI: https://doi.org/10.1016/j.jnnfm.2008.05.003

10. Sho Asakura, Fumio Oosawa J. Polymer Science Part A: General Papers, 1958, vol. 33, no. 126, pp. 183-192. DOI: https://doi.org/10.1002/pol.1958.1203312618 
11. Bishop K. J., Wilmer C. E., Soh S., Grzybowski B. A. Small, 2009, vol. 5, no. 14, pp. 1600-1630. DOI: https://doi.org/10.1002/smll.200900358

12. Hai-Dong Deng, Guang-Can Li, Hai-Ying Liu. Optics Express, 2012, vol. 20, no. 9, p. 9616. DOI: https:// doi.org/10.1364/oe.20.009616

13. Jessy L. B., Asaph Widmer-Cooper, Michael F. T., et al. Nano Letters, 2010, vol. 10, pp. 195-201. DOI: https:// doi.org/10.1021/n1903187v
14. Wulfert R., Seiferta U., Speck T. Soft Matter, 2017, vol. 13, no. 48, pp. 9093-9102. DOI: https://doi.org/10.1039/ c7sm01737e

15. Hong-Ren Jiang, Hirofumi Wada, Natsuhiko Yoshinaga, Masaki Sano. Physical Review Letters, 2009, vol. 102, p. 208301. DOI: https://doi.org/10.1103/physrevlett.102.208301
Долгих Игорь Игоревич - аспирант кафедры физики полупроводников и микроэлектроники, Воронежский государственный университет, Воронеж, Россия; тел.: +7 (908) 1468527, e-mail: dolgih igor@yahoo.com

Битюикая Лариса Александровна - к. х. н., доцент кафедры физики полупроводников и микроэлектроники, Воронежский государственный университет, Воронеж, Россия; тел.: +7 (951) 8789667, e-mail:me144@mail.ru
Igor I. Dolgih - Postgraduate Student, Department of Physics of Semiconductors and Microelectronics, Voronezh State University, Voronezh, Russia; tel.: +7 (908) 1468527, e-mail: dolgih_igor@yahoo.com

Larisa A. Bitutskaya-Cand. Sci. (Chem.), Associate Professor of the Department of Physics of Semiconductors and Microelectronics, Voronezh State University, Voronezh, Russia; tel.: +7 (951) 8789667, e-mail:me144@mail.ru 